\title{
Quantitative analysis of combustion process of marine dual fuel engine under the framework of iconology
}

\author{
Hongliang Yu*, Weiwei Wang*, Shulin Duan** and Peiting Sun** \\ * School of Ocean, Yantai University, No. 30, Qingquan Road, Laishan District, Yantai, 264005, China \\ ** Marine Engineering College, Dalian Maritime University, Dalian, 116026, China \\ * Corresponding author email: yuhongliang19852@163.com
}

Submitted :09/07/2019

Revised :07/03/2021

Accepted : 15/03/2021

\begin{abstract}
The methane $\left(\mathrm{CH}_{4}\right)$ burning interruption factor and the characteristic values characterizing the flame combustion state in the engine cylinder were defined. The logical mapping relationship between image feature values and combustion conditions in the framework of iconology was proposed. Results show that there are two periods of combustion instability and combustion stability during the combustion of dual fuel. The high temperature region with a cylinder temperature greater than $1800 \mathrm{~K}$ is the largest at $17^{\circ} \mathrm{CA}$ after top dead center (TDC), accounting for $73.25 \%$ of the combustion chamber area. During the flame propagation, the radial flame velocity and the axial flame velocity are "unimodal" and "wavy," respectively. During the combustion process, the $\mathrm{CH}_{4}$ burning interruption factor first increased and then decreased. The combustion duration in dual fuel mode is $21.25^{\circ} \mathrm{CA}$, which is $15.5^{\circ} \mathrm{CA}$ shorter than the combustion duration in pure diesel mode.
\end{abstract}

Keywords: Dual fuel engine; Diesel/natural gas; Combustion interruption; Flame velocity.

\section{INTRODUCTION}

At present, natural gas as a ship clean fuel is called research hotspot in the field of marine engines (JS Holladay and J Lariviere, 2017). The stability of the combustion process of dual fuel engines is receiving more and more attention (Yu Hongliang et al., 2017). Good combustion stability is a basic requirement for safe, economical, and clean operation of the engine. V. Vuorinen et al. (2014) established a large vortex turbulent jet model for natural gas engines. The finite volume method was used to simulate the in-cylinder injection process. The results show that the methane jet mixing speed is fast, and when methane is injected and burned in the engine cylinder, the concentration of the jet exhibits a concentration difference in different combustion chamber zones. B. Yadollahi and M. Boroomand. (2013) numerically simulated a small high-speed in-cylinder direct-injection natural gas engine by calculating the multidimensional model and the finite volume method in the combustion method and studied the influence of five different piston head forms on the turbulence of the combustion process during single-hole injection.

Xiang La et al. (2018), based on the in-cylinder process model established on the Matlab/Simulink platform, proposed a new calculation method of the heat release rate of blended gas engine, calculated the heat release rate 
under different substitution ratio, and analyzed the influence of natural gas substitution ratio on the combustion characteristics of blended gas engine. Michailidis et al. (2013) conducted a low-temperature combustion test of different gas-liquid fuel blending ratios for a single-cylinder high-speed dual-fuel engine. The results show that the low-temperature combustion conditions with interval injection are compared with the gas-liquid fuel blending ratio. The increase in the in-cylinder pressure is significant, and the NOx emissions are reduced. Li Meng-han et al. (2016) used a test method to conduct three sets of comparative experiments on an electronically controlled supercharged direct injection natural gas engine and analyzed the effects of speed, load, rail pressure, and fuel injection timing on hydrocarbon generation.

P Sombatwong et al. (2013) and Li Wei-feng et al. (2015) and others conducted research on different fuel injection quantities, and Ryu (2013), Lee (2013), and Dong Quan et al. (2017) conducted research on gas injection characteristics. Although many researchers have extensively explored various performance optimization methods for dual-fuel engines through experimental research and computational fluid dynamics (CFD) calculations, the experimental research method is applicable to small- and medium-sized engines, and hundreds of thousands of largescale low-speed dual-fuel engines for ships. The research methods for data collection have limitations on site and equipment (Yu Hongliang et al., 2016). The result data of CFD calculation is mainly based on two-dimensional curve and three-dimensional cloud image. The two-dimensional curve can effectively study the macroscopic law. The threedimensional cloud image can display the intracylinder distribution during the combustion process of the engine, but for a specific feature. Quantitative research is not possible, and it is often estimated by humans that the research results are deviated from the real situation (Zhang Bo et al., 2016). Most researchers are limited to comparing performance under different conditions and have not studied the combustion process quantification and combustion stage control. In particular, there is a lack of systematic research on quantitative methods of combustion processes.

In order to more accurately study the combustion process of marine low-speed two-stroke dual-fuel engine, the idea of imaging is used to regard the combustion process of the engine as an overlay of infinite in-cylinder instantaneous images, and the in-cylinder transients in the combustion process through image algorithm were quantified. This paper takes a marine natural gas/diesel dual-fuel engine as the research object. Based on iconology, the logical mapping relationship between image feature value and combustion state under the iconology framework is proposed, and the characteristic values reflecting the flame combustion state in the engine cylinder are defined. The instantaneous combustion state was transformed into a matrix change for analysis, and the eigenvalue, combustion duration, and $\mathrm{CH}_{4}$ combustion interruption in the dual fuel combustion process were quantitatively studied.

\section{ICONOLOGY ANALYSIS ALGORITHMS AND MODELS}

The gradation transformation method of the image enhancement algorithm in iconology and the gradient operation of the image segmentation algorithm are used, in the quantification study of each substance in the cylinder.

\section{Gray Scale Conversion Method}

The gradation transformation method is a method of converting the gradation value of image pixel points by performing point calculation on the image in the spatial domain. The general process is to represent the gray value of the original image as a function $f(x, y)$. After the point operation $t=G(f)$, it is converted into the gray value function $t(x, y)$ of the new image, namely,

$$
t(x, y)=G[f(x, y)]
$$


According to the characteristics of multivariable combustion in the in-cylinder combustion process of dual fuel engines and the processing methods of point operations, linear and segmentation gray-scale transformation forms are adopted in this paper.

(1) Linear grayscale transformation

The used field of the original image gray function $f(x, y)$ is $[a, b]$, and through the linear transformation of the pixel point, the used field of the new image gray function $t(x, y)$ is $\left[a^{\prime}, b^{\prime}\right]$, and then the linear transformation process formula is

$$
t(x, y)=a^{\prime}+\frac{b^{\prime}-a^{\prime}}{b-a}(f(x, y)-a)
$$

\section{(2) Segmental grayscale transformation}

The piecewise gradation transformation first divides the spatial domain into different use fields and uses the gradation function in the domain to discriminate. The gradation function conforming to the research purpose will be converted in the use domain, and the gradation function that does not meet the research purpose is directly weakened or skipped.

If gray maximum of original image is $M_{f}$, the used field of the gray value function $f(x, y)$ of the original image is $\left[0, M_{f}\right]$, which corresponds to the gray-scale used field of the research purposed as $[a, b]$, the used field after the piece-wise gray-scale transformation is $[c, d]$, and the gray maximum after the piece-wise gray-scale transformation is $M_{g}$, and the piece-wise gray-scale transformation process formula is

$$
t(x, y)=\left\{\begin{array}{cc}
(c / a) f(x, y) & 0 \leq f(x, y)<a \\
{[(d-c) /(b-a)][f(x, y)-a]+c} & a \leq f(x, y)<b \\
{\left[\left(M_{g}-d\right) /\left(M_{f}-b\right)\right][f(x, y)-b]+d} & b \leq f(x, y) \leq M_{f}
\end{array}\right.
$$

\section{Gradient Operation}

Let $\mathrm{f}(x, y)$ be the original image:

$$
\nabla f(x, y)=\frac{\partial f}{\partial x}+\frac{\partial f}{\partial y}=G x+G y
$$

Its strength is

$$
A=\sqrt{G x^{2}+G y^{2}}
$$

Its direction is

$$
\alpha=\operatorname{tg}^{-1}(G y / G x)
$$


If the image can be digitized, a differential format can be used:

$$
\begin{gathered}
\partial f / \partial x \rightarrow f(i, j)-f(i-1, j) \\
\partial f / \partial y \rightarrow f(i, j)-f(i, j-1) \\
\nabla f(i, j)=2 f(i, j)-f(i-1, j)-f(i, j-1)
\end{gathered}
$$

Using a second-order matrix can be expressed as

$$
\left[\begin{array}{cc}
0 & -1 \\
-1 & 2
\end{array}\right]
$$

Similarly, the second-order differential Laplacian operator (Feng Jinmei et al., 2014) is

$$
\begin{aligned}
& L(i, j)=4 f(i, j)-[f(i-1, j)+f(i, j-1)+f(i+1, j)+f(i, j+1)] \\
& \text { The use of a third-order matrix can be expressed as }\left[\begin{array}{ccc}
0 & -1 & 0 \\
-1 & 4 & -1 \\
0 & -1 & 0
\end{array}\right] .
\end{aligned}
$$

\section{Logical Mapping Under The Framework of Graphics}

The in-cylinder transient image obtained by numerical calculation can predict the combustion process in the engine cylinder, but it is a numerical image calculated by software. In the quantitative analysis of the combustion process, the numerical image must be digitized; that is, the successive image field quantization processes are performed in the form of an array matrix in different gray levels.

If the numerical image gray sampling function is $f(x, y)$, the spatial sampling function is $g(x, y)$, and the digital function of the numerical image obtained by sampling and grading in the whole region is

$$
F(x, y)=f(x, y) \cdot g(x, y)
$$

where

$$
g(x, y)=\sum_{i=0}^{n} \sum_{j=0}^{m} \delta(x-i \Delta x, y-j \Delta y)
$$

In the formula, $\triangle x$ and $\triangle y$ are the interval area for the function matrix $\delta, n$ is the number of pixels in the axis direction, and $m$ is the number of pixels in the radial direction. 

image:

Substituting equation (10) into equation (9) gives the global digitization function of the transient numerical

$$
F(x, y)=f(x, y) \cdot g(x, y)=\sum_{i=0}^{n} \sum_{j=0}^{m} f(i \Delta x, j \Delta y) \cdot \delta(x-i \Delta x, y-j \Delta y)
$$

Quantify $F(x, y)$ to get the matrix:

$$
F(x, y)=\left[\begin{array}{cccc}
F(0,0) & F(0,1) & \cdots & F(0, M-1) \\
F(1,0) & F(1,1) & \cdots & F(1, M-1) \\
\cdots & \cdots & \cdots & \cdots \\
F(N-1,0) & F(N-1,1) & \cdots & F(N-1, M-1)
\end{array}\right]
$$

The matrix shown in equation (12) is a digital image for quantitative analysis, and the points in the matrix row represent pixels in the numerical image. In the quantitative analysis, the three-dimensional model obtained by the calculation is sliced, and the numerical image of each slice is processed by gray scale change and gradient operation and converted into a data matrix. The logical mapping under the framework of the iconology is shown in Figure 1.

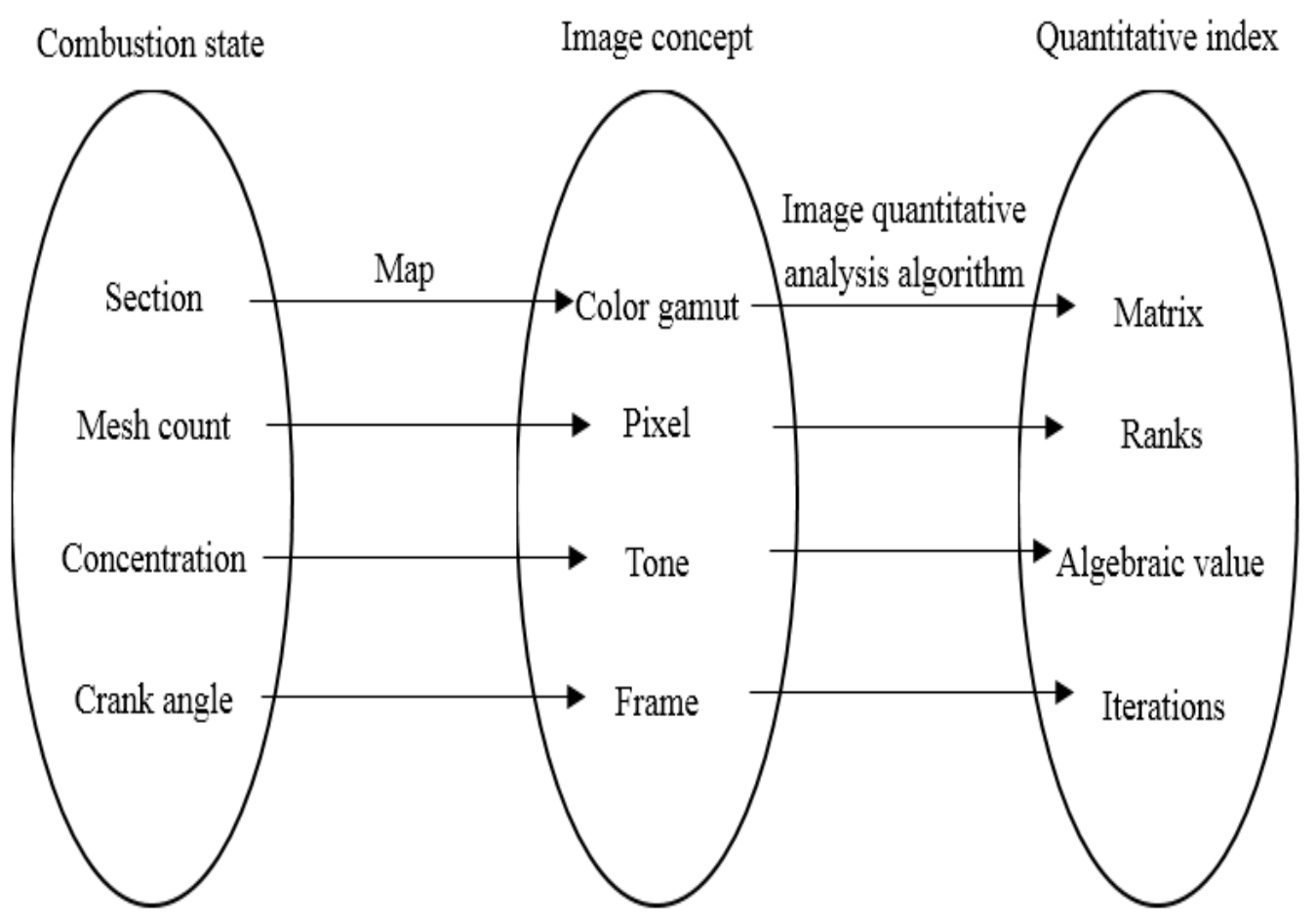

Figure 1. Logical mapping in the framework of iconology. 


\section{Combustion Eigenvalue Definition}

In order to better quantify the in-cylinder combustion state of the engine, this paper proposes three eigenvalues that stated the characteristics of the combustion process, and it can reflect the stability of flame combustion and can also reflect the development law of flame propagation. Therefore, the definition of combustion eigenvalues is critical to the quantitative analysis of the combustion process. In the quantitative analysis of the combustion process, it is necessary to extract the characteristic value of the flame image and establish a reasonable threshold value to establish the relationship between the combustion eigenvalues and the combustion process in the cylinder. In this paper, the combustion process is analyzed by the eigenvalues of the area value and area variation in high temperature region, high temperature region rate and high temperature region change rate, and high temperature flame propagation velocity of the cylinder. The flame image eigenvalues are defined as follows:

(1) The area value and area variation in high temperature region

The natural gas combustion process in the dual-fuel engine cylinder changes instantaneously, and the stability of the combustion process is mainly reflected by the variation of the flame area in the high temperature region. The high temperature zone area refers to the area of the zone corresponding to the combustion temperature in the cross section of the in-cylinder instantaneous combustion process along the cylinder axis and passing through the nozzle above $1800 \mathrm{~K}$. The instantaneous flame image can be transformed into a matrix of gray values by the image quantitative analysis algorithm. The area occupied by each gray value in the matrix is a fixed size, and the gray value above the threshold is extracted, and all the extracted gray values are occupied. The area is the area of the flame in the high temperature region, expressed by $S_{h}$, and the calculation formula is

$$
S_{h}=\sum_{i=1}^{X} \sum_{j=1}^{Y} L\left[f\left(x_{i}, y_{j}\right)-g\right]
$$

where $L(x)$ is a step function, which is defined as $L(x)=\left\{\begin{array}{ll}1 & x \geq 0 \\ 0 & x<0\end{array}\right.$.

$X$ and $Y$ are the number of pixels along the axial direction $x$ and the radial direction $y$ in the instantaneous image of the in-cylinder combustion process, $f\left(x_{i}, y_{j}\right)$ are the gray values of the pixel points in the $j$-th row and the $i$-th column in the image matrix, and $g$ is the gray-scale threshold of the high temperature region.

The area change calculation of the flame in high temperature region under the image is used crank angle as frame. $\triangle S_{h k}$ is the area change in high temperature region in the $k$-th frame. The calculation formula is

$$
\Delta S_{h \mathrm{k}}=S_{h \mathrm{k}}-S_{h \mathrm{k}-1}
$$

(2) High temperature region rate and high temperature region change rate

The high temperature region ratio is the ratio of the high flame temperature region in the gray area of the combustion chamber, and the rate of change of the high temperature region is the ratio of the amount of change in the high temperature region to the gray area of the combustion chamber. The stable high-temperature combustion zone is the main body of natural gas combustion in the dual-fuel engine cylinder and can improve the anti-interference 
ability of the combustion process. $H$ refers to the rate of change of high temperature region, $I$ refers to the area ratio of high temperature, and the calculation formulas are

$$
H=\frac{\Delta S_{h}}{S_{r}} \text { and } I=\frac{S_{h}}{S_{r}}
$$

where $S_{r}$ is the area of the combustion chamber image.

(3) High temperature flame propagation velocity

The flame propagation velocity is the linear velocity of the flame moving forward on the surface of the combustion object in unit time, and the flammable gas characterizes the moving velocity of the flame front in the combustion process in space. The high temperature flame propagation velocity in the cylinder can be calculated by calculating the distance of the high temperature flame boundary movement per unit time. The in-cylinder instantaneous image is sliced per unit time, and the high-temperature flame boundary is segmented in the image processing. The coordinates of the pixel $A$ on the boundary are $\left(x_{i}, y_{j}\right)$, and the distances $\triangle l$ are the continuous two frames of $A$.

$$
\Delta l=\sqrt{\left(x_{i+1}-x_{i}\right)+\left(y_{j+1}-y_{j}\right)}
$$

Then, the high temperature flame propagation velocity $v$ is

$$
v=\Delta l / \Delta t
$$

where $\triangle t$ is the time interval of two frames.

\section{Calculation Model}

Modeling and meshing were done by using AVL-FIRE software. The model and grid of marine dual fuel(DF) engine combustion chamber were shown in Fig. 2. Combustion chamber and the fuel injector were axis symmetrical structure, so the calculation region of the engine took the original engine grid, the combustion chamber diameter was $500 \mathrm{~mm}$, the axial distance of the combustion chamber area at top dead center is $204 \mathrm{~mm}$, and dynamic grid length was $2000 \mathrm{~mm}$. The technical specifications of the engine were given in Table 1. The properties of fuels were given in Table 2. 


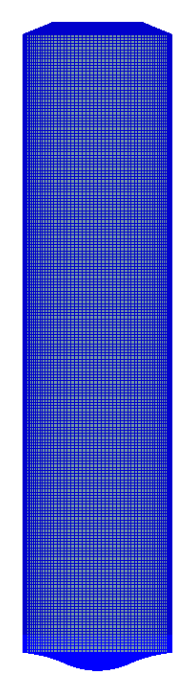

(a) $-138^{\circ} \mathrm{CA}$
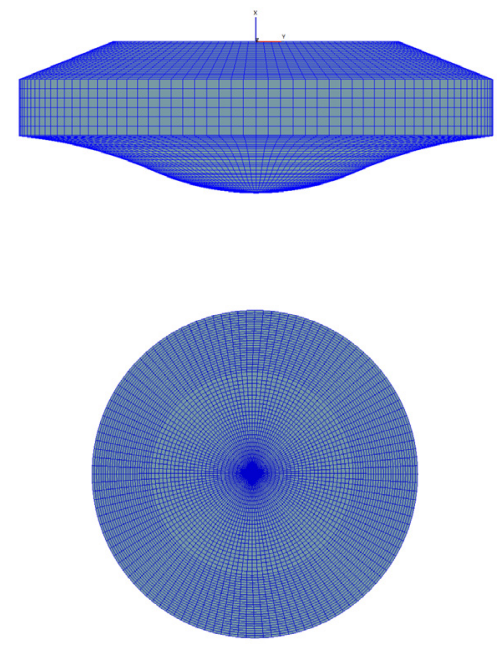

(b) $0^{\circ} \mathrm{CA}(\mathrm{TDC})$

Figure 2. The model and grid of combustion.

Table 1. Technical parameters.

\begin{tabular}{|c|c|}
\hline Item & Parameter \\
\hline Bore $/ \mathrm{mm}$ & 500 \\
\hline Stroke $/ \mathrm{mm}$ & 2000 \\
\hline Fuel system type & Direct Injection \\
\hline Method of aspiration & Turbo-charging \\
\hline Maximum cylinder pressure $/ \mathrm{MPa}$ & 16.17 \\
\hline Main timings $/{ }^{\circ} \mathrm{CA}$ & 4 BTDC \\
\hline Pilot timings $/{ }^{\circ} \mathrm{CA}$ & 6 BTDC \\
\hline
\end{tabular}


Table 2. Properties of fuels.

\begin{tabular}{|c|c|c|c|}
\hline \multicolumn{2}{|c|}{ Diesel Properties } & \multicolumn{2}{|c|}{ LNG Properties } \\
\hline Low heat value $/(\mathrm{MJ} / \mathrm{kg})$ & 42.51 & High heat value/(MJ/m3) & 38.234 \\
\hline Density/( $\left.\mathrm{kg} / \mathrm{m}^{3}\right)$ & 849.4 & Relative density & 0.609 \\
\hline Viscosity/cSt & 3.14 & Rhon $/\left(\mathrm{kg} / \mathrm{m}^{3}\right)$ & 0.733 \\
\hline \multicolumn{2}{|c|}{ Diesel Elemental Analysis } & \multicolumn{2}{|c|}{ LNG Elemental Analysis } \\
\hline Carbon $/(\% \mathrm{~m} / \mathrm{m})$ & 86.74 & $\mathrm{CH}_{4} /(\% \mathrm{~V} / \mathrm{V})$ & 92.682 \\
\hline Hydrogen/(\% m/m) & 12.95 & $\mathrm{C}_{2} \mathrm{H}_{2} /(\% \mathrm{~V} / \mathrm{V})$ & 4.175 \\
\hline Nitrogen $/(\% \mathrm{~m} / \mathrm{m})$ & 0.14 & $\mathrm{C}_{3} \mathrm{H}_{8} /(\% \mathrm{~V} / \mathrm{V})$ & 0.184 \\
\hline Oxygen $/(\% \mathrm{~m} / \mathrm{m})$ & 0.04 & $\mathrm{IC}_{4} \mathrm{H}_{10} /(\% \mathrm{~V} / \mathrm{V})$ & 0.094 \\
\hline \multirow[t]{6}{*}{ Sulphur/(\% m/m) } & 0.06 & $\mathrm{NC}_{4} \mathrm{H}_{10} /(\% \mathrm{~V} / \mathrm{V})$ & 0.130 \\
\hline & & $\mathrm{IC}_{5} \mathrm{H}_{12} /(\% \mathrm{~V} / \mathrm{V})$ & 0.069 \\
\hline & & $\mathrm{NC}_{5} \mathrm{H}_{12} /(\% \mathrm{~V} / \mathrm{V})$ & 0.029 \\
\hline & & $\mathrm{C}_{6}^{+} /(\% \mathrm{~V} / \mathrm{V})$ & 0.301 \\
\hline & & $\mathrm{N}_{2} /(\% \mathrm{~V} / \mathrm{V})$ & 0.613 \\
\hline & & $\mathrm{CO}_{2} /(\% \mathrm{~V} / \mathrm{V})$ & 1.723 \\
\hline
\end{tabular}

The calculation assumes that the pressure and temperature in the initial state of the cylinder are uniform everywhere. The cylinder is a closed system during the whole calculation process, and the heat exchange process is calculated according to the boundary conditions of the given wall temperature. The calculation starts from the scavenging port closing time $138^{\circ} \mathrm{CA}$ before top dead center (BTDC) to the exhaust valve opening time $114^{\circ} \mathrm{CA}$ after top dead center (ATDC) ends, and the top dead center is $0^{\circ} \mathrm{CA}$. In the calculation, the $\mathrm{k}-\varepsilon$ double equation turbulence model (Yu Hongliang et al., 2015) widely used in engineering is selected to simulate the flow field in the internal combustion engine cylinder. In the spray calculation, the Walljet1 model (Zhang Zhou-rong et al., 2015) was used to simulate the spray wall-breaking process. The Wave (AVL FIRE, 2008) model was used to simulate droplet breakage, and the droplet evaporation was simulated using the Multicomponent (O. Samimi Abianeh et al., 2014) model. The Coherent Flame (I.Gy. Zsély et al., 2011) combustion model is used to calculate the transmission, ignition, and combustion processes of each component. The emission model uses the commonly used Extended Zeldovich NOx model (Xu Zhou et al., 2015) and the Kennedy/Hiroyasu/Magussen soot emission model (Jiang Bing et al., 2015). 


\section{RESULTS AND DISCUSSION}

\section{Experiment Setup and Model Verification}

To ensure the validity of the test, all instruments are calibrated prior to the test. The marine dual fuel engine operates in propeller propulsion characteristics in pure fuel mode. Start the engine, gradually adjust the load and speed, adjust the engine oil and water system operating parameters to the optimal value, and run the engine for 30 minutes under the maximum continuous rating (MCR) 25\% load (power $1950 \mathrm{~kW}$, speed $68 \mathrm{r} / \mathrm{min}$ ), and then measure the maximum burst pressure, compression end pressure, turbine front and rear exhaust temperature, scavenging pressure, scavenging temperature, air mass flow, fuel mass flow, exhaust mass flow, exhaust pressure, gas emission data, etc. Gradually adjust the fuel supply to increase engine power and speed. Correspondingly run for 30 minutes in $50 \%$ load (power $3900 \mathrm{~kW}$, speed $85.7 \mathrm{r} / \mathrm{min}$ ) and $75 \%$ load (power $5850 \mathrm{~kW}$, speed $96.1 \mathrm{r} / \mathrm{min}$ ) and run at $100 \%$ load (power $7800 \mathrm{~kW}$, speed $108 \mathrm{r} / \mathrm{min}$ ) for 60 minutes; after the engine is running stably, the operating data and emission data under each corresponding load are measured. The operational data is used as the initial condition for the calculation, and the emission data is used to verify the calculation results. The test was carried out on a test cell of a marine diesel engine. The main instruments tested are shown in Table 3.

Table 3. Test Cell Information.

\begin{tabular}{|c|c|c|c|}
\hline Analyzer & Model & Measurement ranges & Deviation \\
\hline $\mathrm{CO} / 10^{-6}$ & AIA-240 & $0 \sim 500$ & $0.09 \%$ \\
\hline $\mathrm{CO}_{2} / \%$ & AIA-240 & $0 \sim 8$ & $0.1 \%$ \\
\hline $\mathrm{NO} / 10^{-6}$ & FAC-246 & $0 \sim 2000$ & $0.1 \%$ \\
\hline $\mathrm{O}_{2} / \%$ & IMA-241 & $0 \sim 25$ & $0.1 \%$ \\
\hline $\mathrm{HC} / 10^{-6}$ & FAC-246 & $0 \sim 2000$ & $0.08 \%$ \\
\hline$t /{ }^{\circ} \mathrm{C}$ & $\mathrm{T} 1308.3-022$ & $0 \sim 600$ & $1 \%$ \\
\hline$p / \mathrm{MPa}$ & $\mathrm{T} 1308.3-013$ & $0 \sim 50$ & $1.6 \%$ \\
\hline $\mathrm{speed} /(\mathrm{r} / \mathrm{min})$ & FC-2010 & $0 \sim 3000$ & $0.1 \%$ \\
\hline $\mathrm{power} / \mathrm{BHP}$ & $\mathrm{CFSR}-26$ & $0 \sim 50000$ & $0.25 \%$ \\
\hline
\end{tabular}

Figure 3 is a comparison of the measured values and calculated values of the highest burst pressure and discharge products in pure diesel mode of marine dual fuel engine. As shown in Figure 3, the numerical results of the in-cylinder explosion pressure, $\mathrm{CO}, \mathrm{NO}, \mathrm{HC}$, and other results agree well with the experimental values, and the experimental data and the calculation result curve line pattern are basically the same, which can ensure the accuracy of the calculation results. 


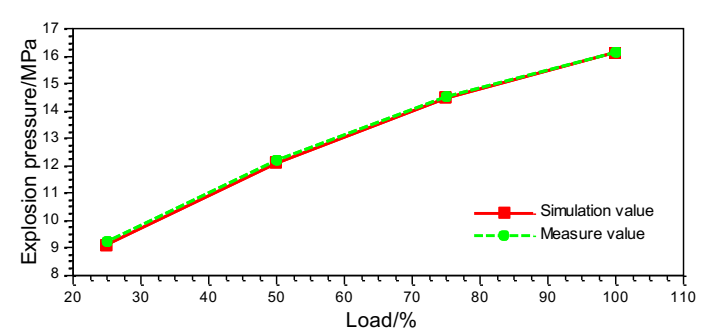

(a) mean pressure

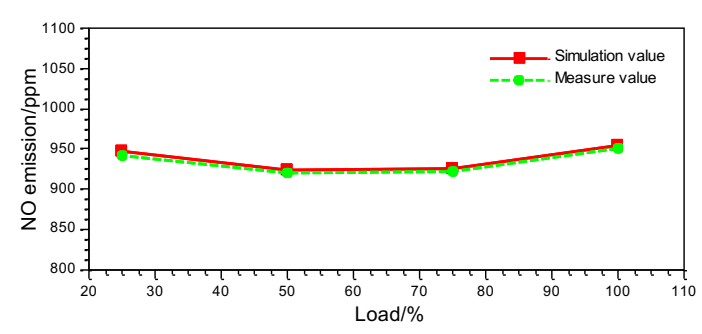

(c) NO emission

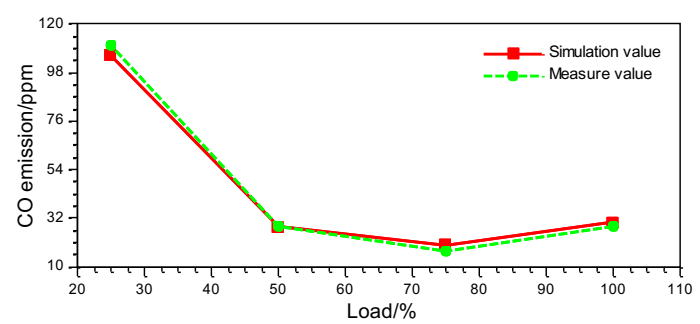

(b) $\mathrm{CO}$ emission

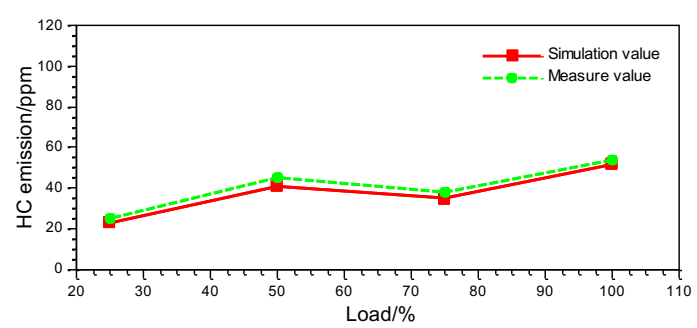

(d) $\mathrm{HC}$ emission

Figure 3. Comparison chart between simulation values and measure values.

\section{Combustion Eigenvalue Analysis}

Figure 4 shows the high temperature region and the variation of high temperature region in the cylinder between $0{ }^{\circ} \mathrm{CA}$ and $20^{\circ} \mathrm{CA}$ ATDC. As shown in Figure 4, the value and variation of the high temperature region are fluctuating during the combustion process. The high temperature region likes a "hill" and has only one maximum during the combustion process, while the variation of the high temperature region is always in a fluctuating state, and the amount of change increases or decreases indefinitely. There are two periods of combustion instability $\left(5^{\circ} \mathrm{CA} \sim 9^{\circ} \mathrm{CA}\right.$ ATDC and $14^{\circ} \mathrm{CA} \sim 20^{\circ} \mathrm{CA}$ ATDC) and a period of combustion stability $\left(9^{\circ} \mathrm{CA} \sim 14^{\circ} \mathrm{CA}\right.$ ATDC) throughout the combustion process. In the first unstable period $\left(5^{\circ} \mathrm{CA} \sim 9^{\circ} \mathrm{CA} \mathrm{ATDC}\right)$, the combustion process fluctuated greatly, the high temperature region increased instantaneously, and the high temperature region change fluctuated sharply. The fluctuation range was from $1.3 \times 10^{4} \mathrm{~mm}^{2}$. $\left(5^{\circ} \mathrm{CA} \sim 6^{\circ} \mathrm{CA} \mathrm{ATDC}\right)$ rapidly reduced to $9.1 \times 10^{3} \mathrm{~mm}^{2}\left(7^{\circ} \mathrm{CA} \sim 8^{\circ} \mathrm{CA}\right.$ ATDC) and further attenuated to $6.6 \times 10^{3} \mathrm{~mm}^{2}\left(8^{\circ} \mathrm{CA} \sim 9^{\circ} \mathrm{CA}\right.$ ATDC $)$. During the stabilization period $\left(9^{\circ} \mathrm{CA} \sim 14^{\circ} \mathrm{CA}\right.$ ATDC), the in-cylinder combustion state is relatively stable, the high temperature region is gradually increased, and the variation of the high temperature region is small, and the average fluctuation range is $5.9 \times 10^{3} \mathrm{~mm}^{2}$. With the gradual development of in-cylinder combustion, the concentration of natural gas in the cylinder gradually decreases, causing a second unstable period $\left(14^{\circ} \mathrm{CA} \sim 20^{\circ} \mathrm{CA}\right.$ ATDC) in the cylinder. Although the high temperature region in the cylinder is gradually increasing, it passes the high temperature. As can be seen from the amount of change in area, the increase in the area of the high temperature is gradually decreasing. After $20^{\circ} \mathrm{CA}$ ATDC, the high temperature region in the cylinder begins to shrink. 

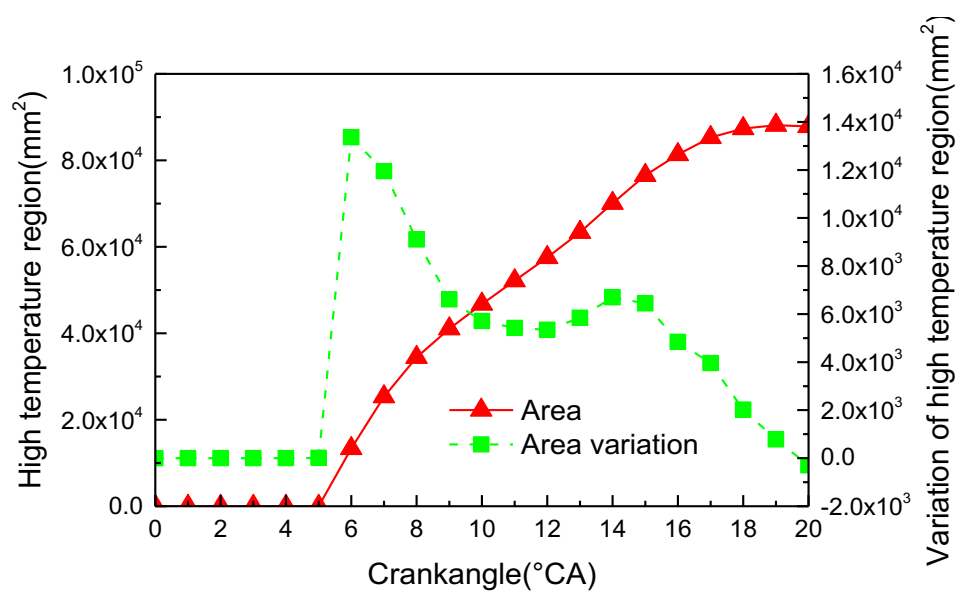

Figure 4. Value and variation in high temperature region.

Figure 5 shows the high temperature region ratio and high temperature region change ratio between $0{ }^{\circ} \mathrm{CA}$ and $24{ }^{\circ} \mathrm{CA}$ ATDC. It can be seen that the high temperature region ratio also increases first and then decreases during the combustion process. The high temperature region ratio increases rapidly during the first unstable period $\left(5^{\circ} \mathrm{CA} \sim 9^{\circ} \mathrm{CA}\right.$ ATDC) and increases gradually during the stable period $\left(9^{\circ} \mathrm{CA} \sim 14^{\circ} \mathrm{CA}\right.$ ATDC), and a decrease occurs after $14^{\circ} \mathrm{CA}$. The maximum is at $17^{\circ} \mathrm{CA}$ ATDC, and the high temperature combustion region in the cylinder accounts for about $73.25 \%$ of the combustion chamber region. The fluctuation ratio of the high temperature region is obvious. In the first unstable period, the combustion process fluctuates greatly. The high temperature region change ratio reaches the maximum at $6^{\circ} \mathrm{CA} \mathrm{ATDC}$, and the newly added high temperature region accounts for $15 \%$ of the combustion chamber area. During the stable period and the second unstable period, the fluctuation ratio of the high temperature region is relatively small compared to the first unstable period, and the change of the high temperature region in the cylinder is gently increased $\left(9^{\circ} \mathrm{CA}\right.$ ATDC $\sim 14^{\circ} \mathrm{CA}$ ATDC) and gently shrinks the trend after $14^{\circ} \mathrm{CA}$ ATDC.

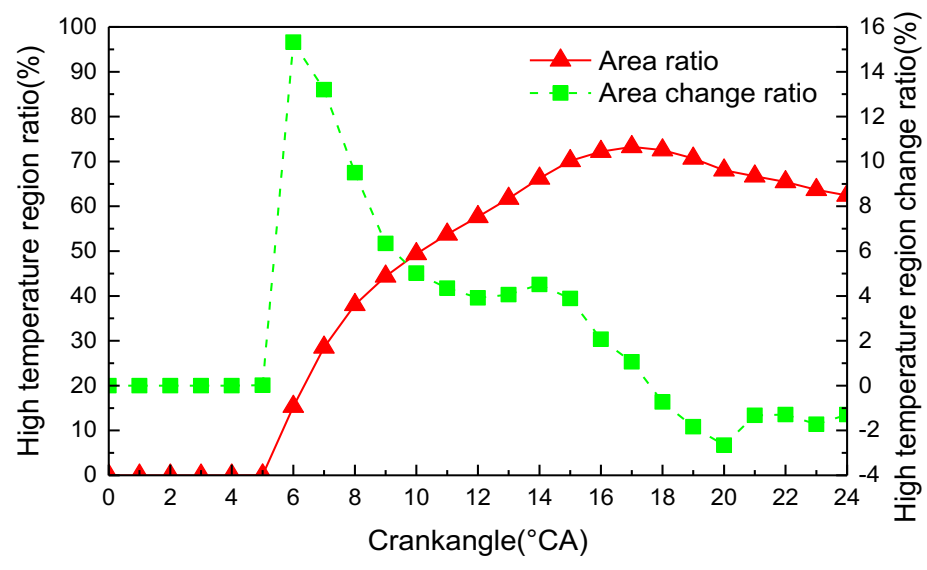

Figure 5. High temperature region rate and high temperature region change rate.

Figure 6 shows the propagation velocity of the in-cylinder flame along the radial and axial directions of the cylinder. As shown in Figure 6, the flame propagation velocity in the entire cylinder exhibits different fluctuations along the radial and axial directions of the cylinder, the radial flame velocity is "unimodal", and the axial flame is and "wavy". Before the $8^{\circ} \mathrm{CA}$ ATDC, the radial flame velocity is much larger than the axial flame velocity. After the 
natural gas catches fire, the flame propagates very rapidly along the cylinder radial direction. At the intersection of the flame fronts on the left and right sides of the cylinder $\left(4^{\circ} \mathrm{CA}\right.$ ATDC), the flame propagation velocity along the radial direction of the cylinder reaches the maximum, and the maximum radial flame propagation velocity reaches $30.9 \mathrm{~m} / \mathrm{s}$. After the flame front meets, the radial flame velocity is rapidly reduced by the flame collision $\left(4^{\circ} \mathrm{CA}\right.$ ATDC $\sim 6^{\circ} \mathrm{CA}$ ATDC). As the natural gas near the nozzle is burned, the radial flame velocity decreases slowly $\left(6^{\circ} \mathrm{CA}\right.$ ATDC $\sim 8^{\circ} \mathrm{CA}$ ATDC). When the flame is at $8^{\circ} \mathrm{CA}$ ATDC, the radial flame develops to the cylinder wall, the radial flame propagation velocity is blocked by the cylinder wall, and the flame propagation velocity is attenuated to zero. The axial flame velocity is also the same as the radial flame velocity. The flame propagation velocity increases rapidly after the ignition in the cylinder. When the flame fronts meet at both sides, the axial flame propagation velocity reaches a maximum value of $8.8 \mathrm{~m} / \mathrm{s}$. The difference is that the flame collision on both sides has a certain enhancement effect on the axial flame, so that the axial flame propagation velocity is slower than the radial flame propagation velocity $\left(4^{\circ} \mathrm{CA}\right.$ ATDC $\sim 6^{\circ} \mathrm{CA}$ ATDC), the axial flame propagation velocity is hindered by the flame propagation at the bottom of the exhaust valve and the upper surface of the piston, and the radial flame propagation has been limited to promote the axial flame propagation. Under the joint action, the axial flame velocity is reduced. The radial flame velocity is slow $\left(6^{\circ} \mathrm{CA}\right.$ ATDC $\sim 8^{\circ} \mathrm{CA}$ ATDC). At $8^{\circ} \mathrm{CA}$ ATDC, the axial flame propagation velocity is hindered by the top of the piston and the bottom of the exhaust valve, and the axial flame propagation velocity is attenuated to zero. As the piston continues to descend $\left(10^{\circ} \mathrm{CA}\right.$ ATDC $\sim 20^{\circ} \mathrm{CA}$ ATDC), the axial flame propagation space continues to increase, and the axial flame propagation velocity appears to slowly increase and slowly decrease the cyclic fluctuation.

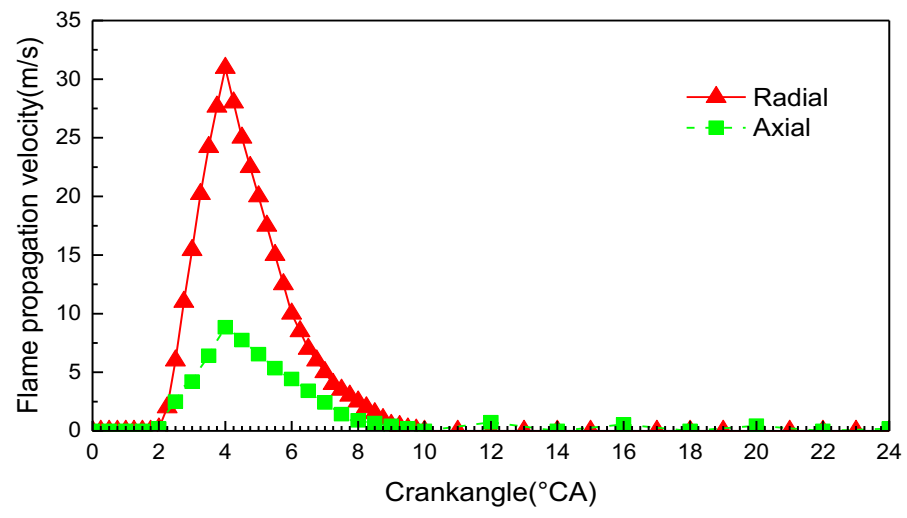

Figure 6. Flame propagation velocity in the cylinder.

\section{$\mathrm{CH}_{4}$ Combustion İnterruption Phenomenon}

Large $\mathrm{CH}_{4}$ emission of the dual fuel engine directly affects engine performance. The main reason for the large $\mathrm{CH}_{4}$ emission is the incomplete combustion in the cylinder. The in-cylinder unburned $\mathrm{CH}_{4}$ after the end of combustion $\left(23.5^{\circ} \mathrm{CA}\right.$ ATDC) was extracted by the image segmentation algorithm. The residual $\mathrm{CH}_{4}$ mass ratio (residual $\mathrm{CH}_{4}$ quantity/ $\mathrm{CH}_{4}$ total quantity) in the cylinder after the end of combustion is shown in Figure 7. At $23.5^{\circ} \mathrm{CA}$ ATDC, the residual $\mathrm{CH}_{4}$ mass ratio in the cylinder is $1.05 \%$. At the beginning of the exhaust valve $\left(114^{\circ} \mathrm{CA}\right.$ ATDC), the residual $\mathrm{CH}_{4}$ mass ratio in the cylinder is $0.04 \%$. 


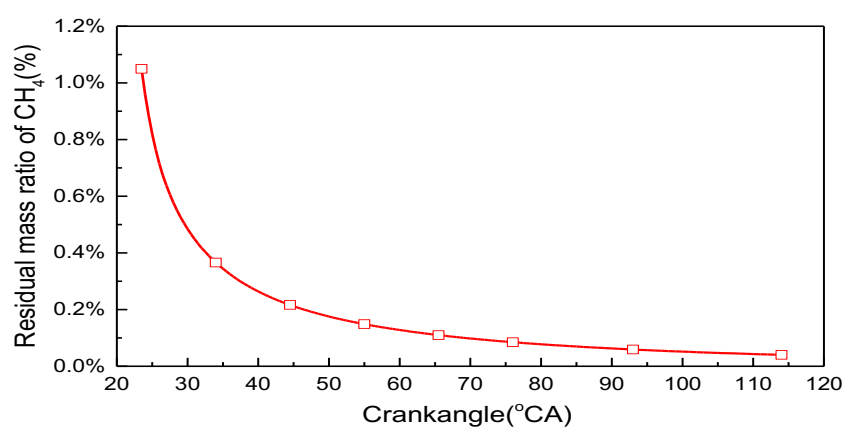

Figure 7. Residual mass ratio of $\mathrm{CH}_{4}$ after combustion end point.

The main reason for the incomplete combustion of $\mathrm{CH}_{4}$ is that the mixing concentration of natural gas in the cylinder does not reach the ignition limit, and the temperature in the cylinder is too low. Therefore, the thermochemical branching reaction caused by the low temperature in the cylinder is interrupted, so that the flame cannot be further propagated. The phenomenon is called a combustion interruption. The spontaneous temperature of natural gas is $650^{\circ} \mathrm{C}$. To further analyze the spatial distribution characteristics of $\mathrm{CH}_{4}$ combustion interruption during the combustion of marine dual-fuel engine, we use the definition of the area, where the in-cylinder temperature is less than $650^{\circ} \mathrm{C}$ and the unburned $\mathrm{CH}_{4}$ equivalent ratio in the cylinder is greater than zero. For the incomplete combustion region of $\mathrm{CH}_{4}$, the extraction and overlap are, respectively, performed by the image algorithm. The incomplete combustion zone in the cylinder at the end of combustion is mainly caused by the interruption of combustion. Therefore, the ratio of the incomplete combustion zone to the total combustion zone is referred to as the burning interruption factor.

Figure 8 shows the variation of the burning interruption factor with the crank angle. As the crank angle increases, the burning interruption factor first increases and then decreases. The reason for the above phenomenon is as follows: natural gas starts to inject at $4{ }^{\circ} \mathrm{CA}$ before top dead center, and the concentration of $\mathrm{CH}_{4}$ in the cylinder rises gradually before ignition, but the temperature lower than $650{ }^{\circ} \mathrm{C}$ region in the cylinder is large during the combustion period. The incomplete combustion area is increasing. When the natural gas is on fire $\left(2.25^{\circ} \mathrm{CA}\right.$ ATDC), the burning interruption factor is not zero. When the natural gas is ignited, the amount of $\mathrm{CH}_{4}$ involved in combustion at the initial stage of combustion increases, but the flame is driven by the fuel beam, propagating around, accelerating the diffusion of $\mathrm{CH}_{4}$, accompanied by the downward movement of the piston, causing the incomplete combustion area to gradually expand, so that the burning interruption factor is increasing. As the combustion continues to develop, the temperature inside the cylinder gradually rises. The complete combustion zone is transformed into a complete combustion zone, and most of the $\mathrm{CH}_{4}$ in the cylinder is burned off, so the burning interruption factor begins to decrease.

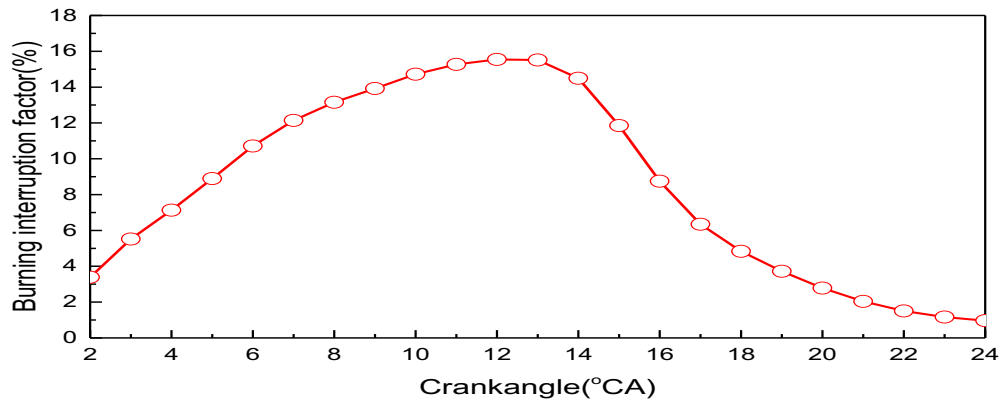

Figure 8. Burning Interruption Factor. 


\section{Burning Stage İn Different Modes}

Figure 9 shows the various combustion stages of a dual fuel engine in different fuel modes. It can be seen from the figure that the combustion process of the dual fuel engine in different fuel modes is obviously inconsistent. Compared with the pure diesel mode, the dual fuel mode has a longer retardation period and a shorter combustion duration. In pure diesel mode, diesel enters the cylinder in the form of small droplets, which requires a certain retardation period for oil droplets to be broken, atomized, evaporated, and mixed with air. However, due to the lower ignition point of diesel, the in-cylinder diesel is easy on fire. In dual fuel mode, natural gas enters the cylinder in gaseous form and only needs to be mixed with air. However, due to the high ignition point of natural gas, the ignition quantity is very low under the ignition condition of only $3 \%$ of pilot diesel. After being put into the cylinder, pilot diesel still has to undergo the process of crushing, atomizing, evaporating, and mixing with oil droplets. It takes a period of time for the diesel to ignite from its own ignition to provide the lowest ignition energy for natural gas. Therefore, the ignition delay period (IDP) in the dual fuel mode is longer than that of the pure diesel mode. In dual fuel mode, once natural gas begins to burn, because natural gas can release higher heat than diesel, the combustible mixture of natural gas and air accumulated in the cylinder will burn rapidly and cause the temperature inside the cylinder to rise rapidly. As a result, the subsequent injection of natural gas accelerates the mixing velocity with air, eventually causing most of the natural gas to be burned during the rapid combustion period (RCP) and deflagration period (DP). Only some of the natural gas that has not reached the concentration of fire is burned during the postcombustion period (PCP). In the pure diesel mode, after the diesel fire, the combustible mixture during the DP and a small portion of the diesel that has reached the combustible concentration are mainly diffused and burned, and the subsequently injected diesel is still in the form of oil droplets. Rapid combustion still has to go through a series of processes to mix with air to achieve flammable mixed gas concentration and conduct diffusion combustion. Therefore, the RCP in pure diesel mode is shorter than the dual fuel mode, and subsequent injection of diesel fuel while burning the DP and the PCP is longer. Therefore, the combustion duration period (CDP) of the dual fuel engine in the dual fuel mode is significantly shorter than that in the diesel mode, especially in the middle and late stages of the combustion process, and the combustion rate of the engine in the dual fuel mode is significantly accelerated.

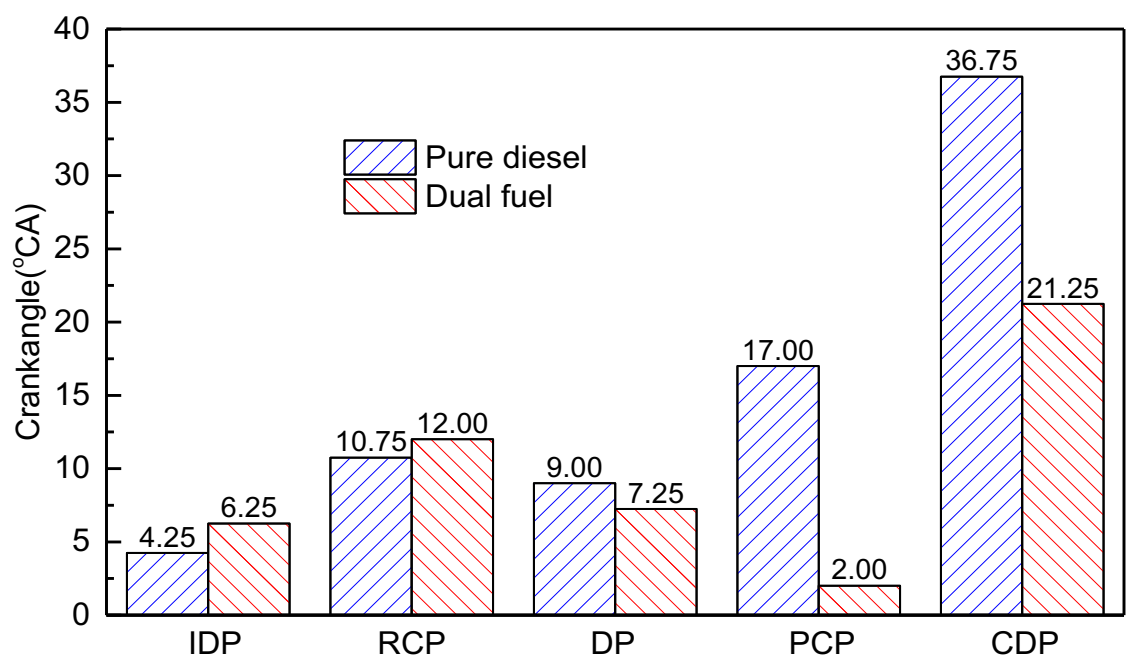

Figure 9. Combustion duration of dual fuel engines under different fuel modes. 


\section{CONCLUSION}

There are two periods of combustion instability and a period of combustion stability during the dual fuel combustion process. The high temperature region with cylinder temperature greater than $1800 \mathrm{~K}$ is the "unimodal" law of increasing first and then decreasing. At $17^{\circ} \mathrm{CA}$ ATDC, the high temperature combustion area in the cylinder is the largest, accounting for $73.25 \%$ of the combustion chamber area.

During the flame propagation, the radial flame velocity and the axial flame velocity are "unimodal" and "wavy", respectively, and the maximum radial flame propagation velocity is 3.5 times the maximum axial flame propagation velocity.

The combustion duration in dual fuel mode is $21.25^{\circ} \mathrm{CA}$, which is $15.5^{\circ} \mathrm{CA}$ shorter than the combustion duration in pure diesel mode. During the combustion process, the $\mathrm{CH}_{4}$ burning interruption factor first increased and then decreased.

The logical mapping relationship between image feature value quantization analysis and combustion status is established based on the basis of iconology, and the eigenvalues reflecting the combustion state of the flame and its calculation method are defined, which contributes to the quantitative analysis of the general development trend of flame combustion and provides useful engineering practical value for real-time judgment of the instantaneous state of the in-cylinder combustion process.

\section{REFERENCES}

AVL FIRE. 2008. AVL FIRE v2008 Description of calculation and control parameters in cylinder. Austria: AVL LIST 2008.

B. Yadollahi, M. Boroomand. 2013. A numerical investigation of combustion and mixture formation in a compressed natural gas DISI engine with centrally mounted single-hole injector. Journal of Fluids Engineering 135(9): 1-9.

Dong Quan, Cai Zhiyong, Song Enzhe, Ma Xiuzhen, Yao Chong, \& Huang Tao. 2017. Characteristics of high-pressure gas jets for natural gas engine based on shock wave calibration. Transactions of CSICE. 35(1):44-52.

Feng Jinmei, Lu Zhimao, Yang Peng, \& Zhang Zihong. 2014. Color image segmentation algorithm based on local priority. J. Huazhong Univ. of Sci. \& Tech. (Natural Science Edition) 9:44-48.

I.Gy. Zsély, T. Nagymailto:tibibyte@ludens.elte.hu, J.M. Simmie, \& H.J. Curran. 2011. Reduction of a detailed kinetic model for the ignition of methane/propane mixtures at gas turbine conditions using simulation error minimization methods. Combustion and Flame 158(8): 1469-1479.

Jiang Bing, Wu Zhaohui, \& He Yuntang. 2015. Effect of combustion chamber's shape of CNG engine on air flow and combustion characteristic. Transactions of the Chinese Society for Agricultural Machinery 46(1):338-344.

JS Holladay, J Lariviere. 2017. The impact of cheap natural gas on marginal emissions from electricity generation and implications for energy policy. Journal of Environmental Economics \& Management 85, 205227.

Lee, J. 2013. Comparison of the effects of multiple injection strategy on the emissions between moderate and heavy EGR rate conditions: part 1-pilot injections. Journal of Mechanical Science and Technology 27(4): $1135-1141$. 
Li Meng-han, Zhang Qiang, Li Guo-xiang, \& Shao Si-dong. 2016. HC emission of high pressure DI diesel pilot-ignited natural gas engine. Journal of Zhejiang University (Engineering Science) http://xueshu.baidu.com/usercenter/data/journal?cmd=jump\&wd=journaluri\%3A\%28d44110a505e42796 \%29\%20\%Е3\%80\%8A\%E6\%B5\%99\%E6\%B1\%9F\%E5\%A4\%A7\%E5\%AD\%A6\%E5\%AD\%A6\%E6\% 8A\%A5\%28\%E5\%B7\%A5\%E5\%AD\%A6\%E7\%89\%88\%29\%E3\%80\%8B\&tn=SE_baiduxueshu_c1gje upa\&ie=utf-8\&sc_f_para=sc_hilight $\% 3$ Dpublish\&sort=sc_cited50(2):341-346.

Li Wei-feng, LIU Zhong-chang, WANG Zhong-shu, \& DOU Hui-li. 2015. Effects of pilot diesel amount and equivalence ratio on combustion of a dual fuel engine under low loads. Transactions of CSICE. 6:481-490.

Michailidis, A.D., Stobart R.K., Mctaggart-Cowan G.P. \& McTaggart-Cowan. 2013. Low temperature combustion optimization and cycle-by-cycle variability through Injection optimization and gas-to-liquid fuelblend ratio. Journal of Engineering for Gas Turbines and Power 135(7):257-265.

O. Samimi Abianeh, C. P. Chen, \& S. Mahalingam. 2014. Modeling of multi-component droplet coalescence in evaporating and non-evaporating diesel fuel sprays. International Journal of Automotive Technology 15(7):1091-1100.

P Sombatwong, P Thaiyasuit, \& K Pianthong. 2013. Effect of pilot fuel quantity on the performance and emission of a dual producer gas-diesel engine. Energy Procedia 34(9):218-227.

Ryu, K. 2013. Effects of pilot injection pressure on the combustion and emissions characteristics in a diesel engine using biodiesel-CNG dual fuel. Energy Conversion and Management 76(12): 506-516.

V. Vuorinen, A. Wehrfritz, C. Duwig, \& B.J. Boersma. 2014. Large-eddy simulation on the effect of injection pressure and density on fuel jet mixing in gas engines. Fuel 130:241-250.

Xiang La, Ding Yu, \& Wang Kui. 2018. Influence of natural gas substitution rate on heat release rate of marine dual fuel engine. Journal of Harbin Engineering University 39(2):317-323.

Xu Zhou, Zeng Zhuo-xiong, \& Xu Yi-hua. 2015. Numerical simulation of a swirling combustor with vortex cooling wall. Journal of Propulsion Technology 36(3):436-442.

Yu Hongliang, Duan Shulin, \& Sun Peiting. 2017. Numerical simulation of combustion progress on dual fuel engines with different turbulence models. Journal of Engineering Research 5(4), 225-235.

Yu Hong-liang, DUAN Shu-lin, \& SUN Pei-ting. 2016. Effect of main/pilot timings on combustion and emission characteristics of marine dual fuel engines. Journal of Propulsion Technology 37(9):1735-1741.

Yu Hong-liang, Duan Shu-lin, \& Sun Pei-ting. 2015. Effect of LNG gasification temperature on combustion and emission characteristics of marine dual fuel engines. Journal of Propulsion Technology 36(9):1369-1375.

Zhang Bo, Ni Kaizao, Wang Linjun, Liu Shijie, \& Wu Lunzhe. 2016. New algorithm of detecting optical surface imperfection based on background correction and image segmentation. ACTA OPTICA SINICA. 9:112-121.

Zhang Zhou-rong, Wang Qian, He Zhi-xia, Dai Li-ming, Wu Yu-qiang, \& Gao Zhi-sheng. 2015. Research of in-cylinder high pressure direct injection and mixture of diesel and natural gas. Journal of Engineering Thermophysics 36(10):2262-2266. 